\title{
Learning and the prefrontal cortex of the cat: Anatomico-behavioral interrelations
}

\author{
HANS J. MARKOWITSCH and MONIKA PRITZEL \\ University of Konstanz, D-775 Konstanz, Postfach 7733, Federal Republic of Germany
}

\begin{abstract}
Relationships between specific learning tasks and ablation of the prefrontal cortex in the cat are reviewed. The cat's prefrontal area is defined, and its anatomical connections are enumerated. Differences in the locus and extent of the so-called frontal association regions that have been reported are described. Effects of prefrontal lesions on various learning tasks are separately reviewed. Several correlations were performed in an attempt to find relationships between prefrontal subareas and learning task performances. In this way, a relation between mediodorsal degeneration and learning impairment was found, and a subdivision of the prefrontal area into at least a dorsolateral and an orbitofrontal part was attempted. Implications of the results of these analyses and additional approaches are discussed.
\end{abstract}

Because of the marked development of the anterior parts of the cerebrum during mammalian evolution (Masterton \& Skeen, 1972; Teuber, 1964b, p. 165), the prefrontal cortex or frontal granular cortex has been, and still is, considered to mediate superior intellectual functions (Gross \& Weiskrantz, 1964; Luria, 1973). Moniz (1936) and Jacobsen (1935, 1936) first undertook a relatively refined examination of this part of the brain, which, since then, "despite 40 years of careful and ingenious experimentation . . . continues to be one of the most puzzling" of cortical areas (Masterson \& Berkley, 1974, p. 292). The only evaluation of the frontal cortex on which there appears to be a modicum of aggreement, even today, is that lesions of the prefrontal cortex lead to a complex functional deficit (Nauta, $1971,1972)$. Even here, investigators have been unable to explain the deeper causes of such deficits or to trace them to specific anatomical rules or mechanisms (Konorski, 1972).

Animal studies were first conducted in primates and extended later to carnivores and rodents. This trend was fostered by the anatomical investigations of Rose and Woolsey (1948) and Akert (1964a) in cat and Leonard (1969) in the rat.

The cat offers, in contrast to monkey and rat, unique advantages which explain its selection as a laboratory animal for the investigation of prefrontal areas. First, the cat's is perhaps the most extensively studied brain, neurophysiologically (Boudreau \& Tsuchitani, 1973), in part due to the relative inexpensiveness of the acquisition, maintenance, and care of the animal. Second, the cat is able to perform relatively complex intellectual tasks (Warren, 1965, 1973) and finally the size and

The authors would like to express their gratitude to Professors R. B. Freeman, Jr. and J. M. Warren for many helpful comments and criticisms, but responsibility' for the assertions made herein remains our own. structure of its brain allow precise electrophysiological and lesion research.

Because of these facts, it seems appropriate to provide a critical review of the results of such work in the cat, with a view to establishing connections between performance in complex learning tasks and lesions in the prefrontal "association" structures. Within this anatomico-behavioral framework, our main aims are to reconsider the anatomical extent of the cat's prefrontal cortex and its subdivisions, to identify the types of learning tasks which can be assigned to prefrontal subregions, to specify further the involvement of the mediodorsal thalamic nucleus in learning tasks, and to describe its projection onto the neocortex.

\section{BRIEF ANATOMICAL SURVEY}

Widely accepted for subprimate species is Rose and Woolsey's (1948) definition of the prefrontal cortex as the projection area of the mediodorsal nucleus (Akert, 1964a; Voneida \& Royce, 1974). While Rose and Woolsey limit the projection to the gyrus proreus, Akert extends it dorsally nearly to the cruciate sulcus and laterally a bit beyond the presylvian sulcus. Posteromedially, both studies take the anterior limbic region as the border of the prefrontal cortex (Akert, 1964b, p. 395). Figures 1, 2 , and 3 present frontal, anterolateral, and medial views of the frontal regions of the cat brain, and indicate the approximate prefrontal extensions after Rose and Woolsey (1948) (identical with the proreal gyrus) and after Akert (1964a, b, p. 395). Figure 2, in particular, reveals clearly the presylvian sulcus between the relatively curved and protruding lateral parts of the frontal poles and the more medial proreal gyrus.

Rose and Woolsey and Akert based their delineations of the frontal cortex of cat on retrograde 


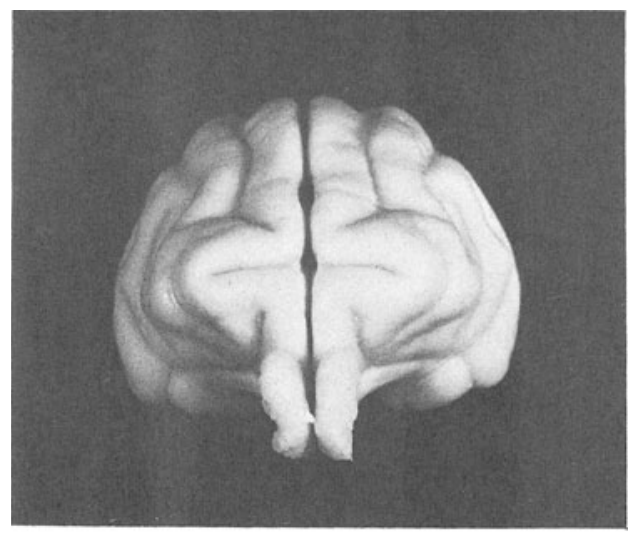

region has been termed "association cortex" owing to the results obtained by lesion studies (Coutant, 1973, 1974; Akert, 1964a), and the same label was given to the pericruciate area in experiments relying on electrophysiological recordings (Albe-Fessard \& Besson, 1973; Dubner, 1966; Mayers, Robertson, Rubel, \& Thompson, 1971). Nevertheless, our review will show that the gyrus proreus continues to be considered the core of the cat's prefrontal cortex (e.g., Beritashvili, 1972; Divac, 1968, 1969, 1972, 1973, 1974; Warren, Warren, \& Akert, 1962).

\section{Connections of the Gyrus Proreus}

To provide an anatomical view of the position

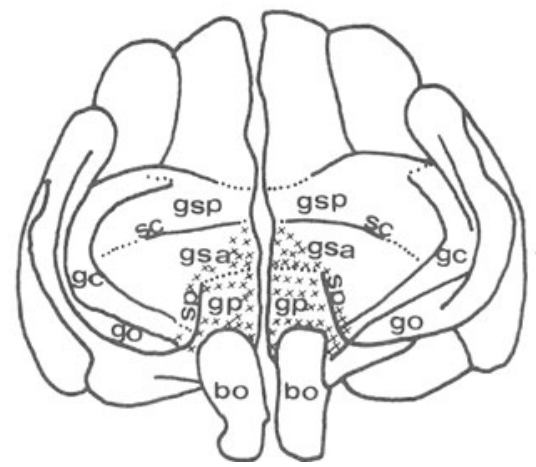
of the proreal gyrus within the cat's brain, direct afferent and efferent connections will be enumerated here.

Afferent fibers. The gyrus proreus has been reported to receive direct cortical afferents mainly from other nonprimary areas, as from its contralateral counterpart (Ebner \& Myers, 1965; Voneida \& Trevarthen, 1969) and from the ipsilateral orbital, anterior sigmoid, and middle suprasylvian gyri (Beritashvili, 1971). Other cortical projection areas are the anterior part of the medial ectosylvian and anterior sylvian gyrus (Beritashvili, 1971). The most prominent subcortical structures belong to the mesencephalic reticular formation and to the limbic lobe, including here septum, amygdala, and the posterior hypothalamus, as well as the cortical cingulate gyrus (Beritashvili, 1971; Webster, 1965). In addition, there are also afferents from the extrapyramidal motor areas (Hassler, 1966; Llamas, Reinoso-Suarez, \& Martinez-Moreno, 1975) and from the dorsomedial thalamic nucleus (Batuev, Molyukova, \& Horyakova, 1974; Guillery, 1959; Khalifeh, Kaelber, \& Ingram, 1965; Rose \& Woolsey, 1948; Waller, 1940; Webster, 1965) and anterior ventral thalamic nucleus (Beritashvili, 1971; Webster, 1965).
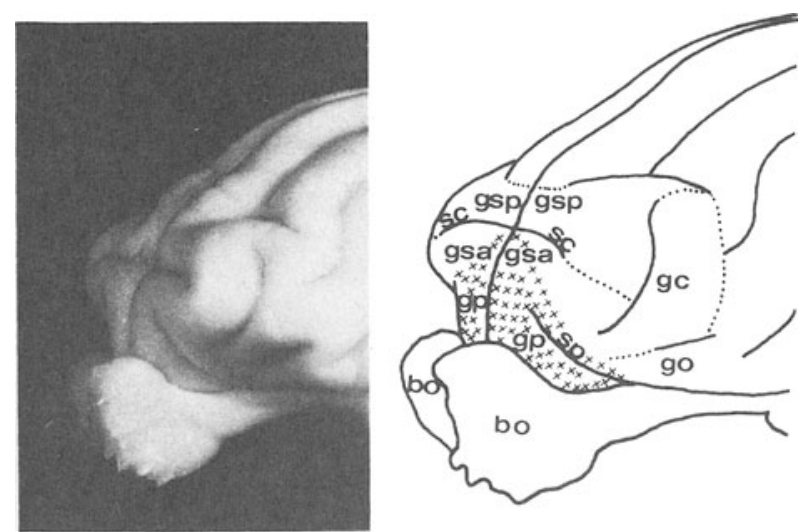

Figure 2. Anterolateral view of the cat's brain. The extent of the prefrontal area is shown (crosses; mainly after Akert, 1964a): symbols are as in Figure 1. The approximate extents of the most important gyri are shown by dotted lines. 
Efferent fibers. Reported cortical efferent connections of the gyrus proreus enter not only such nonprimary areas as the contralateral gyri and rectus (Ebner \& Myers, 1965; Voneida \& Trevarthen, 1969) and the sigmoid, coronal, orbital, presylvian, suprasylvian, and anterior lateral gyri (Astruc, 1969; Voneida \& Trevarthen, 1969), but also primary regions such as the motor, auditory, olfactory, and visual cortex (Astruc, 1969; Heath \& Jones, 1971; Voneida \& Trevarthen, 1969). Many fibers cross the midline to the opposite hemisphere via the rostrum of the corpus callosum (Voneida \& Royce, 1974) and via the anterior commissure (Beritashvili, 1971). Besides the mesencephalic reticular formation (Auer, 1956; Voneida \& Trevarthen, 1969) and the cingulate gyrus (Heath \& Jones, 1971; Voneida \& Royce, 1974; Voneida \& Trevarthen, 1969; Webster, 1965), there are strong projections to the extrapyramidal motor system (Hassler, 1966), including all three basal ganglia and the red nucleus (Beritashvili, 1971; Voneida \& Trevarthen, 1969; Webster, 1965), to the contralateral trigeminal nuclei (Beritashvili, 1971; Voneida \& Trevarthen, 1969; Webster, 1965), to the contralateral trigeminal nuclei (Beritashvili, 1971; Brodal, 1971; Wold \& Brodal, 1974) and to the trapezoid body (Beritashvili, 1971) on the medullia and pons level, to tegmentum and periaqueductal gray on the midbrain level (Beritashvili, 1971; Voncida \& Trevarthen, 1969), and to the dorso1965; Auer, 1956; Rinvik, 1968a; Voneida \& Trevarthen, 1969) thalamus, subthalamus (zona incerta, fields of Forel) (Voneida \& Trevarthen, 1969), hypothalamus (Auer, 1956; Rosvold \& Mishkin, 1961), and preoptic area (Siegel, Edinger, \& Lowenthal, 1974), all at the diencephalic level. The alleged existence of efferents to one of the basal ganglia (globus pallidus) and to the hypothalamus has been questioned by Mettler (1972) and Raisman (1970), respectively.

Summarizing the anatomical connections, it appears that afferent connections to the proreal gyrus arrive via the nonprimary areas and transmit largely processed sensory information which is, or may be, further influenced by the general arousal level of the animal (reticular formation) and by the emotional coloration arising from the limbic system. More complicated is the wide distribution of efferent connections of the proreal gyrus which, like a rebound mechanism, must affect primary as well as nonprimary sensory cortical inputs, as well as the arousal and emotional states of the animal. Possible overt (motoric) reactions seem to be strongly influenced too. The involvement of multiple thalamic fibers might modify sensory, motor, affective, and motivational states.

In spite of the necessary brevity of this listing of the afferent and efferent connections of the cat's proreal gyrus, three aspects of their significance
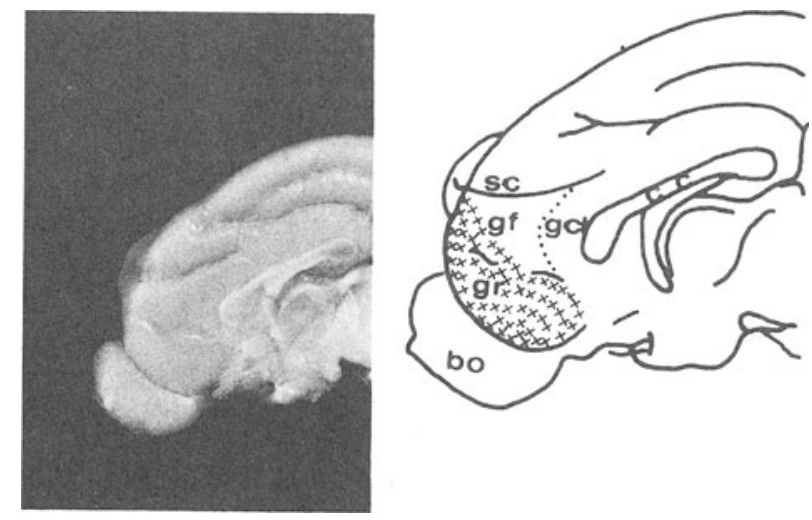

Figure 3. Medial view of the cat's brain. The extent of the prefrontal area is shown (crosses; mainly after Akert, 1964a, b, and Warren, Warren, \& Akert, 1962): bo = bulbus olfactorius, cc $=$ corpus callosum, gci $=$ gyrus cinguli, $\mathrm{gf}=$ gyrus frontalis, $g r=$ gyrus rectus, $s c=$ sulcus cruciatus. The approximate boundary between gyrus frontalis and gyrus cinguli is shown by the dotted line.

should be emphasized. First, both the cytoarchitectonics and the projections of the cat's proreal gyrus support the conclusion that it is a distinct part of the frontal brain; secondly, because of the quantity and diversity of its connections, it appears to be a region meeting all the requirements of a truly associative area; and thirdly, known fiber connections suggest that even within the gyrus proreus, there might be two main functional circuits, a limbic-emotional one, and a motoric one.

\section{RESULTS OF LEARNING STUDIES}

Summarized in the following review are results of investigations of learning in cats whose prefrontal region, including the main parts of the proreal gyrus and parts of the surrounding cortical structures, had been lesioned bilaterally. We limit our analysis to reports of lesion studies because in cats-contrary to rhesus monkeys (e.g., Fuster, 1973; Niki, 1974a, b, c; Stamm \& Rosen, 1969, 1972)-data relating electrophysiological events in the prefrontal area to performance on learning tasks are all but nonexistent.

\section{Delayed Tasks}

In delayed tasks, typically a piece of food is hidden under one of two identical cups or behind one of two (or more) identical covered boxes (e.g., Fletcher, 1965; Watanabe, 1974; Weiskrantz, 1968; Yarbrough, 1917). After a delay, the animal is allowed to choose one of the boxes. In the delayed response task, the animal is shown directly or by means of a discriminative cue under which of two cups (e.g., right or left) the food is hidden. In this task, the position $(R, L)$ of the bait is randomized. In the delayed alternation task, the reward is 
reversed from trial to trial (sequence RLRL), and in the delayed double alternation task, it is reversed every second trial (sequence RRLL). Contrary to the delayed response task, both alternation tasks provide no external cues to food location.

Although severe and permanent impairment in learning and retention of delayed tasks had often been found in lesioned monkeys (e.g., Gross \& Weiskrantz, 1962), deficits have not appeared to the same degree in prefrontal lesioned cats. Instead, a more transient and/or milder impairment in retention of the delayed response (Divac, 1968, 1969, 1973; Lawicka, 1969; Lawicka \& Konorski, 1961), of delayed alternation (Divac, 1972), and of double alternation (Warren, 1964; Warren et al., 1962) tasks have been found after prefrontal ablation in the cat. Only Divac (1974) reports a clear retention deficit after prefrontal lesions. Relearning of the problems was possible, in some cases even with savings (Divac, 1972, 1974; Warren, 1964; Warren et al., 1962). When learning of these tasks was begun postoperatively, prefrontal groups did not differ significantly from control groups in either trials or errors to criterion (Thompson, 1968; Warren, 1964; Warren et al., 1962; Wikmark \& Warren, 1972); in contrast to the results of studies in young monkeys (e.g., Akert, Orth, Harlow, \& Schlitz, 1960; Harlow, Blanquist, Thompson, Schlitz, \& Harlow, 1968), Thompson (1968) discovered that prefrontal kittens exhibited the same kinds of error responses in a delayed task as did adult lesioned cats.

The errors committed by prefrontal cats during the learning of delayed tasks have been grouped into: (a) bodily orientation errors, (b) preference and omission errors, and (c) perseverative errors (Lawicka, 1959; Lawicka \& Konorski, 1961). In these and other studies (Divac, 1968; Thompson, 1968), perseverative errors were found to be most characteristic of the deficit in performing delayed tasks after prefrontal lesions.

The results of such investigations suggest that impairment of performance in the cat on delayed tasks is not representative of the substantial losses resulting from similar lesions of the prefrontal area observed in the cat's performance in other types of tasks (Warren, 1964).

\section{Reversal Tasks}

Performance of the cat on reversal tasks (Coutant \& Warren, 1966; Cronholm, Warren, \& Hara, 1960; Hirayoshi \& Warren, 1967; Warren, 1966) and especially on the spatial reversal task (Warren, Warren, \& Akert, 1972) appears to be more sensitive to prefrontal lesions. In reversal tasks, the animal is rewarded for responding to one stimulus or position either until it has reached a prescribed criterion of correct.responses or for a predetermined number of trials, after which the reward is then changed to the other stimuius with the result that the cat has to select the previously incorrect object.

Warren and his co-workers (Warren, 1964; Warren, Coutant, \& Cornwell, 1969; Warren et al., 1962,1972 ) conducted a thorough analysis of learning and retention performance by prefrontal cats subjected to reversal tests. Their results indicate, for spatial reversal tasks, both severe learning and retention deficits in frontal animals which are somewhat modified in severity and duration by additional variables like training and recovery times (Warren et al., 1962, 1972), discriminability, familiarity or novelty of the objects used as stimuli (Warren, 1964; Warren et al., 1972), and distribution of the reversals with time (Warren et al., 1969).

Performance on nonspatial discrimination reversal reveals a larger behavioral variance than on spatial reversal, ranging from a severe and persistent performance loss (Teitelbaum, 1964; Warren et al., 1969) through recovery after numerous (up to 60) reversals (Warren et al., 1972) to no significant differences between operates and controls in learning (Warren et al., 1962; Zielinski \& Czarkowska, 1974) and retention (Warren, 1964).

Taken together, these results, all but one (Zielinski \& Czarkowska, 1974) of which were obtained using positive reinforcement, demonstrate that prefrontal cats show marked perseveration effects (inability to shift from one response to another; Brutkowski, 1965), resulting chiefly from the effects of distracting stimuli (such as familiar or identical objects) in tasks requiring the inhibition of response due to a change of the stimulus-reward conditions. The combination of spatial and reversal requirements seems to enhance overt deficits, confirming results of lesions in the monkey. Here the efficacy of the spatial and reversal variables are assigned to the dorsolateral and orbital frontal lesions, respectively, and an interaction effect is postulated to explain the more severe and permanent deficits in spatial reversal tasks (Mishkin, 1964; Mishkin, Vest, Waxler, \& Rosvold, 1969; Rosvold, 1968).

Impairments in reversal (and doubtless also in other) tasks have also been attributed to the severity of the degeneration of the mediodorsal thalamic nucleus after prefrontal lesions, perhaps irrespective of the exact size or extent of the prefrontal lesions. Warren et al. (1969) took this criterion to divide their lesioned cats into several groups. One group revealed severe degenerative changes throughout almost the entire length of the mediodorsal nucleus, and included two animals with proreal ablations and two with combined ablations of the pericruciate and proreal gyri. All four animals were significantly inferior in reversal learning to other brain-damaged animals, which also had proreal 
or pericruciate lesions, or both, but in which degeneration of the mediodorsal nucleus was less severe.

\section{Other Tasks}

Several other tasks provide evidence that frontallobe lesions impair the mastering of higher cortical functions in the cat. The reason for the majority of these studies was to explore further an assumed impairment of response inhibition and/or perseverative tendencies (e.g., Brutkowski, 1965). These tasks included discrimination learning, go/no-go, and multiple-choice learning, schedule-based problems, pure active and passive avoidance and escape tasks (with discrimination between several stimuli), and generalization and extinction. The effects $c$ : frontal lesion on these various types of tasks will now be described.

Discrimination learning. Prefrontal cats generally perform as well as normal cats in visual discrimination problems (Warren, 1964; Warren et al., 1962), the exception being sophisticated, trained cats, which seem postoperatively to lose their previously acquired capacity to inhibit responses to preferred, but incorrect, stimuli (Warren et al., 1962).

Spatial discrimination learning, on the other hand, worsens in cats whose frontal cortex has been destroyed. Stepien and her colleagues (Stepien, 1974; Stepien, Stepien, \& Sychowa, 1966) lesioned the pericruciate region, which they refer to as that zone whose destruction leads to the "magnet reaction." such animals show an excessive orienting response to the conditioned stimulus, instead of carrying out the preoperatively properly learned reaction. This syndrome became apparent in an experimental setting in which the cat began each trial in front of two lateralized feeders with loudspeakers nearby. The cat is required to react to the right auditory cue by going 10 the left feeder, and vice versa. After pericruciate surgery, the cats consistently approached the feeder on the same side as the auditory cue. Relearning progressed much slower and was only possible after additional guidance training in some animals.

Go/no-go problems. In go/no-go problems, the animal is required to respond to one stimulus and to withhold responding to another one. Prefrontal cats did not differ significantly from normal cats in learning go/no-go discriminations involving posilive (Coutant, 1973; Warren et al., 1969) and negative reinforcement (Zielinski \& Czarkowska, 1973, 1974). There is again some covariance between the degree of mediodorsal degeneration and go/no-go performance (Warren et al., 1969) and an indication that the lesion interferes with further consolidation of inhibitory reflexes during no-go trials (Zielinski \& ('zarkowska, 1973).

Multiple-choice tasks. The Hebb-Williams maze (illustrations in Rabinovitch \& Rosvold, 1951) requires animals to run through several different labyrinths. Entrances into blind alleys are scored as errors (elapsed time to reach the goal is not recorded). Warren, Warren, and Akert (1961) reported that cats with incomplete prefrontal ablations did not diffel from normals in original learning but had significantly lower saving scores in a retention retest $1 / 2-1 \frac{1}{2}$ years later in comparison with control cats tested after about $1 \frac{1}{2}$ years. With a much larger frontal ablation, including the pericruciate and Akert's frontal granular cortex, cats were impaired in learning Hebb-Williams test problems (Coutan:, 1974).

In the Hamilton search test (illustrated in Warren, 1959), in which animals are required to search for food lying in one of four visually identical boxes, prefrontal cats behaved as well as normals (Warren \& Warren, 1966).

Schedule-based tasks. A type of procedure that requires the withholding (inhibition) of a response are the schedule-based tasks (Richelle, 1972), such as the differential reinforcement of low rates (DRL) (Glickstein, Quickley, \& Stebbins, 1964; Kramer \& Rilling, 1970) and fixed-interval schedules (FI) (Pribram, 1959). Reinforcement is time-based in the FI procedure, irrespective of the number of the animal's reactions, while in DRL tasks the animal must withhold its reaction for a specified interval to receive positive reinforcement.

In cats, Numan and Lubar (1974) analyzed the interactions between proreal damage and DRL performance in a statistically careful study. The extent of the proreal lesion (especially if the ventral sector of the gyrus proreus was included) correlated well with the deficit. Lesions in the anterior sigmoid and coronal gyri and in the pericruciate area (but sparing the gyrus proreus) did not impede DRL acquisition. DRL learning in prefrontal cats improved to the level of the control group only during an intermediate period of time when an external cue (light bulb) signaled the end of the response-withhold period.

Intermediate between the DRL and FI problems lies a variation of the fixed-ratio (FR) schedulc introduced by Wagman (1968). In this task, the subjects are required to produce a fixed number of responses on one bar (count bar) prior to emitting an additional response on another bar (shift bar). Aspiration of the proreal area severely affected retention performance in five of the seven cats used in Wagman's study. Responses to the count bar were reduced from about six to a maximum of around four, and became more variable. The introduction of an external light cue reinstated the preoperative performance level, which was then maintained with only slight loss even after removal of the light cue. Wagman's results are in congruence with Numan and Lubar's (1974) observation that an 
external cue is sufficient to inhibit premature reactions in prefrontal cats. Wagman interprets her results in terms of Teuber's (1966) theory, which implicates the frontal lobes in sensori-motor functioning (see ANATOMICO-BEHAVIORAL INTERRELATIONS below). This theory can explain Wagman's results if one assumes that a response feedback system has been altered by frontal lesions.

Passive avoidance learning. In passive avoidance learning, the animal is trained not to approach a positively reinforced stimulus by being punished if it does. Besides a slight tendency towards reduced avoidance in frontal cats observed in only one of two experiments (Cornwell, 1966), prefrontal and control cats generally did not differ in this testing situation (Cornwell, 1966; Warren et al., 1972). Prefrontal cats can therefore learn to inhibit responses as well as normals, at least under the specific conditions of passive avoidance learning.

Active avoidance and escape learning. Active avoidlance learning is said to occur when the subject learns to perform an appropriate overt response after the onset of a specific signal (CS) in order to avoid an aversive stimulus (US). If it fails to react within the CS-US interval, but responds after the onset of the US, an escape response is said to occur.

Retention of learned avoidance and/or escape reactions is transiently impaired after prefrontal lesions (Nielson \& Davis, 1966; Zielinski, 1966, 1970, $1972 \mathrm{it}, \mathrm{b})$, but the latency of the responses is lengthened postoperatively over long periods (Zielinshi, 1966, 1970, 1972a, b, 1974). The learning deficency of cats whose prefrontal area has been destr yed is also transient when learning is conducted in a one-way shuttlebox (Cornwell, 1966), but avoidance in a two-way apparatus (both compartments are occasionally associated with shock) is retarded (Axelrod \& Diamond, 1965; Warren et al., 1972).

A point of controversy may arise from the loci of the lesions. In one study, these included the entire frontal pole of both hemispheres extending far in both lateral and superior directions (Axelrod \& Diamond, 1965). Other experiments combined lesions of most of the proreal and orbital gyri (Zielinski, 1966, 1970, 1972a, b, 1974) or merely of a part of the gyrus proreus and most of the anterior and posterior sigmoid gyri (Nielson \& Davis, 1966). And Cornwell (1966) distinguished between proreal (prefrontal) and orbital lesioned cats, the performance of the last-named being inferior to the proreal and a control group.

Because of the divergence in extent of lesions, one shoúld exercise restraint in furthér interpretation of the published results of investigations using active avoidance and escape learning.
Generalization. Coutant (1973) showed that prefrontal cats generalized in the same way as control animals to stimulus variants requiring both go (respond) and no-go (inhibit) responses.

Extinction. For postoperatively learned habits (manipulatory reactions), the response probability decreased after initiation of extinction sessions (omission of previously given reward following the same response) in prefrontal lesioned cats as well as in normals (Cornwell, 1966; Warren et al., 1969), while the extinction of a previously acquired running response is significantly retarded in prefrontal cats (Warren et al., 1969). As in other experiments of Warren et al. (1969), the cats with severe mediodorsal degeneration behaved worst but did not show any consistent response decrement in a postoperatively learned task.

\section{ANATOMICO-BEHAVIORAL INTERRELATIONS}

Based primarily on observations of lesion-induced behavioral deficits in monkeys, several authors have attempted an integration of effects of prefrontal lesions and performance. They account for diverse results by splitting the (pre)frontal cortex into two or more subfields to which specific functions are then attributed. The aim of this functional and morphological fractionation (Konorski, 1972) is to establish a one-to-one relationship between brain structure and behavior. As theories and data included here are based mainly on the primate's frontal pole, we must keep in mind the fact that generalization to the carnivore might not be possible in every case.

For the purpose of analysis, the prefrontal cortex of the monkey has usually been divided functionally (as well as anatomically) into a dorsolateral and an orbitofrontal region (Brutkowski, 1964, 1965; Konorski, 1972, 1973; Pribram, 1973; Rosvold, 1968; Teuber, 1964a, 1966, 1972). Teuber (1972) terms the functional distinction the up-dowh gradient. Anatomical connections have been found between the dorsolateral frontal cortex and the anterodorsal sector of the nucleus caudatus (Brutkowski, 1965; Konorski, 1972; Rosvold, 1968) as well as with subthalamus and hippocampus (Brutkowski, 1965). By contrast, the orbitofrontal cortex has connections with the ventrolateral sector of the caudate nucleus (Rosvold, 1968) and with the anterior insula, temporal pole, and the periamygdaloid complex (Pribram, 1973). Authors are in less agreement about the functional association of the two fields. The dorsolateral cortex is assumed to be a center whose destruction results in response perseveration (Brutkowski, 1965), in motor act disinhibition (Konorski, 1972), and in an inability to handle spatial cues (Pribram, 1973; Rosvold, 
1968: Of these, the spatial factor is most frequently mentioned and was further analyzed by Pohl's experiment (1973; see also Pribram, 1973), which suggested the existence of two cortical foci for processing spatial stimuli, a parietal for external cues, and a frontal for internal ("egocentric") cues. On the other hand, the orbitofrontal cortex is said to be an emotional center which regulates (hunger-) drive inhibition (Brutkowski, 1965; Konorski, 1972) or programs whether or not the animal will respond (Rosvold, 1968).

While the up-down gradient is now well established, at least for interpreting primate learning results, newer primate studies have also found evidence for a second gradient (within the dorsolateral cortex), called "back-to-front" by Teuber (1972). This second gradient has its foci in the sulci arcuatus and principalis. Spatial functions are assigned to the former, mnemonic to the latter (Teuber, 1972).

Assuming specific anatomico-behavioral interrelations, we have tried to integrate learning results further by defining behavior controlled by the prefrontal regions. Though different reports use quite different types of data, their conclusions are similar. In short, all suppose that the frontal cortex receives input from sensory centers, integrates this input, and effects motoric responses of the animal (Konorski, 1972; Pribram, 1973; Rosvold, 1968; Teuber, 1966, 1972). All authors, too, stress the dorsolateral cortex more than the orbitofrontal. More specifically, Rosvold's hypothesis is that both the frontal lobes and the basal ganglia regulate activity of the motor system. Teuber $(1966,1972)$ supposes that frontal lobes and basal ganglia preset "the sensory regions in the brain at the onset of voluntary motor acts, preparing the sensory system for those changes that result from normal execution of the intended movement" (Teuber, 1966, p. 284). And Pribram (1973) develops a neuronal model (see his Figure 11), dealing with his assumptions that the frontal regions "internally organize a context upon which behavior must depend"' (p. 312) in situations where an external structure is insufficient.

Common to all theoretical approaches is an only occasional reference to feline data. A probable reasen for this is the scarce and equivocal evidence for specific "within" frontal association areas in the cat. Though the tradition for a partition of the frontal lobes can be traced back to Jacobsen (1935), who looked for the focus of the delayed response task by performing selective incomplete lesions in the prefrontal area of the monkey, this search has so far been successful only in monkeys (Butter, 1969; Iversen \& Mishkin, 1970; Oscar-Berman, 1975; Passingham, 1972a, b; Passingham \& Ettlinger, 1972), dogs (Dabrowska,
1971, 1972), and rats (Kolb, Nonneman, \& Singh, 1974).

We have therefore attempted to compare and reorganize the observations resulting from lesions in specific frontal (sub)areas of the cat's cortex.

\section{Procedure}

Three types of quantitative analyses of the published literature were undertaken. First, we surveyed types of lesions and resulting mediodorsal thalamic degeneration in 30 representative investigations. Secondly, we evaluated the overall extent of fronıal and prefrontal damage and the resulting deficits on various behavioral tasks. Finally, we have correlated the extent of lesions in various parts of the frontal and prefrontal cortex with the magnitude of behavioral deficits in learning and retention with a view to determining those areas of the frontal and prefrontal cortex which are most clearly related to the performance of the tasks in question.

Structures which can be related to the prefrontal cortex are the entire gyrus proreus (dorsalis and ventralis), the gyrus sigmoideus anterior, the lateral wall of the presylvian sulcus, the gyrus rectus, and the anterior portion of the gyrus frontalis (cf. Figures 1-3). As the lateral wall of the presylvian sulcus reaches into the anterior parts of the coronal and orbital gyri, the anterior parts of the latter structures are also subsumed under areas related to the prefrontal cortex. The posterior regions of the gyri sigmoideus, coronalis, and orbitalis, however, cannot be considered as prefrontal, but are referred to as frontal areas.

Within the cat's prefrontal cortex, we have also tentatively distinguished a dorsolateral from an orbital prefrontal region. Included in the former are major portions of the gyri sigmoideus anterior, proreus dorsalis and ventralis, and frontalis anterior. The latter includes the gyrus rectus and the gyrus orbitalis anterior.

A summary analysis of the anatomical and behavioral results of the 30 investigations surveyed is presented in Tables 1 and 2 . Table 1 shows schematically the extent of lesions, the kinds of illustrations of the frontal brain that are shown in the publications cited, and the degree of mediodorsal degeneration (if referred to in the study). Table 2 provides measurements of the overall extent of the frontal and prefrontal lesions reported and the magnitude of impairment of learning and retention after surgery.

The degeneration of the mediodorsal nucleus and the magnitude of lesioned subareas reported in the investigations listed in Table 1 were first rated independently by the two authors. In those cases where no a priori conformity had been achieved, the extent of lesions was rerated. Basically, each subarea 
Table 1

Overview of Lesion Extents, Rated Thalamic Degenerations, and Illustrations in Relevant Studies

\begin{tabular}{|c|c|c|c|c|c|c|c|c|c|c|c|}
\hline \multirow[b]{2}{*}{ Study } & \multicolumn{9}{|c|}{ Lesion Extent of Different Subareas $\mathbf{s}^{\mathbf{a}, \mathbf{b}}$} & \multirow{2}{*}{$\begin{array}{c}\text { Rated } \\
\text { Degree } \\
\text { of Medio- } \\
\text { dorsal } \\
\text { Degenera- } \\
\text { tionc } \\
\end{array}$} & \multirow{2}{*}{$\begin{array}{c}\text { Brain } \\
\text { View } \\
\text { Illustrated } \\
\text { in Studyd }\end{array}$} \\
\hline & $\mathrm{Gpv}^{*}$ & Gpd* & Gsa* & Gsp/a & Goa* & Gop & $\mathrm{Gca}^{*}$ & Gr* & Gfa* & & \\
\hline Axelrod and Diamond $(1965)^{e}$ & $\mathbf{X}$ & $\mathbf{X}$ & $\mathbf{X}$ & $\mathbf{X}$ & $\mathbf{X}$ & $\mathbf{O} / \mathrm{X}$ & $\mathbf{X}$ & $\mathbf{X}$ & $\mathbf{X}$ & 2 & ----- \\
\hline Cornwell $(1966)^{f}$ & $\mathbf{0} / \mathbf{X}$ & $\mathbf{X}$ & $\mathbf{O}$ & O & 0 & 0 & $\mathbf{O}$ & $?$ & $?$ & & $--\cdots--$ \\
\hline Coutant (1973) & $\mathbf{X}$ & $\mathbf{X}$ & $\mathbf{X}$ & $\mathbf{X}$ & $\mathbf{X}$ & 0 & $\mathbf{X}$ & $\mathbf{X}$ & $\mathbf{X}$ & 2 & ----- \\
\hline Coutant (1974) & $\mathbf{X}$ & $\mathbf{X}$ & $\mathbf{X}$ & $\mathbf{X}$ & $\mathbf{X}$ & 0 & $\mathbf{X}$ & $\mathbf{X}$ & $\mathbf{X}$ & 2 & --+++ \\
\hline Divac $(1968,1969)$ & $\mathbf{X}$ & $\mathbf{X}$ & $\mathbf{O}$ & $\mathbf{0}$ & 0 & $\mathbf{0}$ & $\mathbf{0}$ & $\mathbf{X}$ & $\mathrm{O}$ & & ++-+- \\
\hline Divac (1972) & $\mathbf{X}$ & $\mathbf{X}$ & $\mathbf{0}$ & 0 & 0 & 0 & 0 & $\mathbf{X}$ & 0 & & ---+- \\
\hline Divac (1973) & $\mathbf{X}$ & $0 / X$ & $\mathbf{O} / \mathbf{X}$ & 0 & $\mathbf{0} / \mathbf{X}$ & O & $\mathbf{0} / \mathbf{X}$ & $\mathbf{X}$ & $\mathbf{O}$ & 3 & ---++ \\
\hline Divac (1974) & $\mathbf{X}$ & $\mathbf{X}$ & 0 & 0 & $\mathbf{X}$ & 0 & $\mathrm{X}$ & $\mathrm{X}$ & $\mathbf{O}$ & 3 & ---+- \\
\hline Lawicka and Konorski (1961) & $0 / \mathrm{X}$ & $\mathbf{X}$ & $\mathbf{O} / \mathbf{X}$ & 0 & 0 & $\mathbf{0}$ & 0 & $\mathrm{X}$ & 0 & & +-+-- \\
\hline Nielson and Davis (1966) & $0 / \mathbf{X}$ & $\mathbf{X}$ & $\mathbf{X}$ & $\mathbf{X}$ & 0 & 0 & 0 & $\mathrm{O} / \mathrm{X}$ & $\mathbf{X}$ & & +---- \\
\hline Numan and Lubar (1974) & $0 / \mathrm{X}$ & $\mathbf{O} / \mathbf{X}$ & 0 & 0 & 0 & 0 & 0 & $\mathrm{O} / \mathrm{X}$ & 0 & & +++-- \\
\hline Stepien (1974) & 0 & 0 & $\mathbf{X}$ & $\mathbf{0}$ & 0 & 0 & 0 & 0 & $\mathbf{X}$ & & -+--- \\
\hline Stepien et al. (1966) & 0 & 0 & $\mathbf{X}$ & 0 & 0 & 0 & 0 & 0 & $\mathrm{X}$ & & $+\dot{t}-\ldots$ \\
\hline Teitelbaum (1964) & $\mathbf{X}$ & $\mathbf{X}$ & O & 0 & 0 & 0 & $\mathrm{O}$ & $\mathrm{X}$ & 0 & & +---- \\
\hline Thompson (1968) & $\mathrm{X}$ & $\mathbf{X}$ & $0 / X$ & $\mathbf{O} / \mathrm{X}$ & 0 & 0 & $\mathrm{O} / \mathrm{X}$ & $\mathrm{X}$ & $\mathrm{O} / \mathrm{X}$ & 2 & ---+- \\
\hline Wagman (1968) & 0 & $\mathrm{O} / \mathrm{X}$ & $\mathbf{X}$ & $\mathrm{O} / \mathrm{X}$ & 0 & 0 & 0 & $\mathrm{O}$ & $\mathbf{X}$ & 2 & ++--- \\
\hline Warren $(1964)^{g}$ & $\mathbf{O} / \mathbf{X}$ & $\mathrm{X}$ & $\mathrm{O} / \mathrm{X}$ & 0 & $\mathrm{O} / \mathrm{X}$ & 0 & $\mathbf{O} / \mathrm{X}$ & $\mathrm{O} / \mathrm{X}$ & $\mathbf{O} / \mathbf{X}$ & & ---- \\
\hline Warren et al. (1969)h & $0 / \mathrm{X}$ & $\mathbf{X}$ & 0 & 0 & $0 / X$ & $\mathrm{O}$ & $0 / X$ & $\mathbf{O} / \mathbf{X}$ & $\mathbf{X}$ & $1,2,3$ & $++++t$ \\
\hline Warren and Warren $(1966)^{\mathrm{g}}$ & $0 / \mathrm{X}$ & $\mathbf{X}$ & $\mathrm{O} / \mathrm{X}$ & 0 & $0 / X$ & 0 & $0 / X$ & $\mathbf{O} / \mathbf{X}$ & $\mathbf{O} / \mathbf{X}$ & & ---- \\
\hline Warren et al. (1961) & $\mathbf{X}$ & $\mathrm{X}$ & $0 / X$ & 0 & $\mathbf{O} / \mathbf{X}$ & 0 & 0 & $0 / X$ & $\mathbf{O} / \mathbf{X}$ & & ---- \\
\hline Warren et al. (1962) & $\mathbf{X}$ & $\mathrm{X}$ & $\mathrm{O} / \mathrm{X}$ & O & $0 / X$ & 0 & 0 & $0 / X$ & $\mathbf{O} / \mathbf{X}$ & 2 & ---+- \\
\hline Warren et al. (1972) & $\mathrm{O} / \mathrm{X}$ & $\mathbf{X}$ & $0 / X$ & 0 & $0 / X$ & $\mathbf{0}$ & $\mathbf{0} / \mathbf{X}$ & $\mathrm{O} / \mathrm{X}$ & $\mathrm{O} / \mathrm{X}$ & 2 & ++-++ \\
\hline Wikmark and Warren (1972) & $\mathbf{O} / \mathbf{X}$ & $\mathrm{O} / \mathrm{X}$ & $\mathrm{O} / \mathrm{X}$ & $\mathrm{O} / \mathrm{X}$ & $\mathbf{O} / \mathbf{X}$ & 0 & $\mathrm{O} / \mathrm{X}$ & $\mathrm{O} / \mathrm{X}$ & $\mathrm{O} / \mathrm{X}$ & 2 & +++++ \\
\hline Zielinski $(1966,1970)$ & $\mathbf{O} / \mathbf{X}$ & $\mathbf{X}$ & 0 & 0 & 0 & $\mathbf{0}$ & 0 & $\mathrm{X}$ & O & & ++-+- \\
\hline Zielinski (1972a) & $\mathrm{O} / \mathrm{X}$ & $\mathbf{X}$ & $\mathbf{O}$ & $\mathbf{0}$ & $\mathbf{O} / \mathbf{X}$ & $\mathrm{O}$ & 0 & $\mathbf{X}$ & $\mathbf{O}$ & & ++-+- \\
\hline Zielinski (1972b) & $\mathbf{O} / \mathbf{X}$ & $\mathbf{X}$ & 0 & $\mathbf{0}$ & $\mathbf{O} / \mathbf{X}$ & O & 0 & $\mathbf{X}$ & 0 & & ----- \\
\hline Zielinski and Czarkowska $(1973,1974)$ & $\mathrm{O} / \mathrm{X}$ & $\mathbf{X}$ & 0 & 0 & $\mathbf{O} / \mathbf{X}$ & 0 & O & $\mathbf{X}$ & 0 & & ++-+- \\
\hline$\Sigma \%^{i}$ & 65 & 85 & 37 & 20 & 32 & 2 & 20 & 77 & 39 & & \\
\hline
\end{tabular}

Note-If several areas were lesioned in different groups of cats, only the relevant (i.e., prefrontal) group is considered. If the presylvian sulcus was destroyed, both the anterior coronal and anterior orbital areas were marked.

${ }^{\mathrm{a}} X=$ at least half of the subarea was lesioned, $O=$ less than half of the subarea was lesioned, $O / X=$ within the experimental group, the lesion extents varied, ? = not indicated.

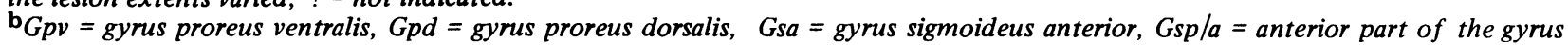
sigmoideus posterior, Goa = anterior part of the gyrus orbitalis, Gop = posterior part of the gyrus orbitalis, Gca =anterior part of the gyrus coronalis, $G r=$ gyrus rectus, $G f a=g y r u s$ frontalis anterior; * indicates that this area is counted as prefrontal.

$c_{1}=$ no remarkable, $2=$ considerable, 3 = severe degeneration of the mediodorsal nucleus.

$\mathrm{d}_{L}=$ lateral, $M=$ medial, $F=$ frontal, $C=$ coronal, $T=$ (mediodorsal) thalamic illustrations appear $(+) /$ do not appear $(-)$ in the corresponding studies.

e Frontals were used as control group only.

f Only the proreal group is considered in this table.

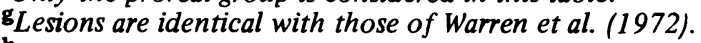

${ }^{\mathbf{h}}$ Experimental groups were recombined in accordance with degree of mediodorsal degeneration.

i $\Sigma \%=$ percent of studies lesioning the particular area $(O / X$ was counted half $)$.

(see Figures 1, 2, and 3) was assigned an $X$ if at least half of its surface appeared to have been lesioned, and an $\mathrm{O}$ is less than half was lesioned. If, within an experiment, the extent of the prefrontal lesions was varied so that in some of the animals more than half of the particular area was destroyed and in some less than half was destroyed, this subarea was assigned an $\mathrm{O} / \mathrm{X}$ symbol. This sign was used irrespective of the proportion of $O$ and $X$ cases, as more, exact ratings were impossible due to the frequency with which specifications were lacking or insufficient. Classifications of lesions in the frontal subareas were based both on the descriptions in the text and on illustrations of the histology for each study. To apply our ratings, we used the pattern of gyri and sulci laid down in Figures 1 to 3 as a reference. The relatively dense pattern of sulci in the region rostrally to the cruciate sulcus helps to identify the borders of small or irregular lesions as well, providing the basis on which we attempted to group the severity of prefrontal lesions. While the dichotomous ratings $X$ and $O$ seemed sufficient for the analysis of frontal lesions, for the degeneration of the mediodorsal nucleus three classifications were more appropriate, a " $l$ " for no remarkable, a " 2 " for considerable, and a " 3 " for severe degeneration. Thalamic degeneration was also estimated from the findings reported by the authors 
and from published illustrations. The resulting values were then averaged for all animals reported, except for those in the study of Warren et al. (1969).

The degree of impairment on learning and retention tasks reported in Table 2 was also first rated independently by the two authors and then rerated in cases of ambiguity. To obtain a reliable determination, we used the following three-level classification: a "1" for no remarkable, a " 2 " for considerable (significant, $\mathrm{p} \sim<.07$ ), and a " 3 " for severe (highly significant, $\mathrm{p} \sim<.01$ ) behavioral changes. Impairment ratings were based on whatever information (results, tables, conclusions) could be gleaned from the studies. The degree of impairment was again averaged for the animals in question, except for the cats in Warren et al. (1969).

Of all ratings shown in Tables 1 and 2, agreement was reached on the first attempt in more than $95 \%$ of the cases; the remaining ratings on which disagreement occurred on the first round were rerated by going over all available data again and discussing the analyses until final concordance was achieved.

\section{Analysis}

Correlations between locus and size of lesions and degree of behavioral deficit have occasionally been attempted with limited success in studies on the rat and cat (Hannon \& Bader, 1974; Numan \& Lubar, 1974; Wikmark \& Warren, 1972). In these investigations, clear relationships between anatomical and behavioral variables either could not be found or were ascribed to other uncontrolled determinants. The variety of morphological and functional variables introduced in other investigations, in which procedures were limited to one type of lesion and/or behavioral measure, complicated the search for one-to-one functional relationships in the prefrontal cortex. Therefore, we performed here an analysis based on rated anatomical and functional values between frontal and control groups within each single experiment, but correlated over all relevant studies. In this way we hoped to neutralize the

Table 2

Relations Between Grouped Learning and Retention Tasks and Rated Deficits

\begin{tabular}{|c|c|c|c|c|c|c|c|c|c|c|c|c|c|c|}
\hline \multirow[b]{2}{*}{ Study } & \multicolumn{2}{|c|}{$\begin{array}{c}\text { Overall } \\
\text { Extent of } \\
\text { Cortex } \\
\text { Destroyed }^{\mathbf{b}}\end{array}$} & \multicolumn{12}{|c|}{$\begin{array}{c}\text { Rated Learning and Retention Deficits of Indicated } \\
\text { Task Groups }{ }^{2}\end{array}$} \\
\hline & Fr. & Prẹfr. & D & DA & DDA & SR & NSR & DI & GNG MC & SB & PA & AA & G & $\mathbf{E}$ \\
\hline $\begin{array}{l}\text { Axelrod and Diamond (1965) } \\
\text { Cornwell (1966) }\end{array}$ & 94.4 & 100 & & & & & & & & & 2 & $\begin{array}{l}2 \\
2\end{array}$ & & 1 \\
\hline Coutant (1973) & 88.9 & 100 & & & & & & & 2 & & & & 1 & \\
\hline Coutant (1974) & 88.9 & 100 & & & & & & & 3 & & & & & \\
\hline Divac $(1968,1969)$ & 33.3 & 42.9 & 2 & & & & & & & & & & & \\
\hline Divac (1972) & 33.3 & 42.9 & & 2 & & & & & & & & & & \\
\hline Divac (1973) & 50.0 & 57.1 & 3 & & & & & & & & & & & \\
\hline Divac (1974) & 55.6 & 71.4 & & 3. & & & & & & & & & & \\
\hline Lawicka and Konorski (1961) & 33.3 & 42.9 & 2 & & & & & & & & & & & \\
\hline Nielson and Davis (1966) & 55.6 & 57.1 & & & & & & & & & & 2 & & \\
\hline Numan and Lubar (1974) & 16.7 & 21.4 & & & & & & & & 3 & & & & \\
\hline Stepien (1974, et al., 1966) & 22.2 & 28.6 & & & & & & 2 & & & & & & \\
\hline Teitelbaum (1964) & 33.3 & 42.9 & & & & & 3 & & & & & & & \\
\hline Thompson (1968) & 55.6 & 64.3 & 2 & & & & & & & & & & & \\
\hline Wagman (1968) & 33.3 & 35.7 & & & & & & & & 3 & & & & \\
\hline Warren (1964) & 50.0 & 50.0 & 2 & & 2 & $3^{\mathbf{c}}$ & $3^{c}$ & 1 & & & & & & \\
\hline Warren et al. (1969) & 50.0 & 57.1 & & & & $2,3^{d}$ & $2,3^{d}$ & & 2 & & & & & $2^{e}, 1^{f}$ \\
\hline Warren and Warren (1966) & 50.0 & 50.0 & & & & & & & 1 & & & & & \\
\hline Warren et al. (1961) & 50.0 & 50.0 & & & & & & & 2 & & & & & \\
\hline Warren et al. (1962) & 50.0 & 50.0 & & & 2 & $2^{\mathbf{c}}$ & $1^{\mathbf{c}}$ & 2 & & & & & & \\
\hline Warren et al. (1972) & 50.0 & 50.0 & & & & $1^{8}$ & $2^{8}$ & & & & 1 & 3 & & \\
\hline Wikmark and Warren (1972) & 50.0 & 57.1 & 2 & & & & & & & & & & & \\
\hline Zielinski $(1966,1970)$ & 27.8 & 35.7 & & & & & & & & & 2 & & & \\
\hline Zielinski (1972a, 1972b) & 33.3 & 42.9 & & & & & & & & & 2 & & & \\
\hline Zielinski and Czarkowska $(1973,1974)$ & 33.3 & 42.9 & & & & & & & 3 & & & & & \\
\hline
\end{tabular}

Note $-F r .=$ frontal, Prefr. $=$ prefrontal, $D=$ delayed response, $D A=$ delayed alternation response, $D D A=$ double delayed alternation response, $S R=$ spatial reversal, $N S R=$ nonspatial reversal learning, $D I=$ discrimination, $G N G=$ go/no-go learning, $M C=m u l t i p l e$ choice, $S B=$ schedule-based, $P A=$ passive avoidance, $A A=$ active avoidance learning, $G=$ generalization, $E=$ extinction.

$\mathrm{a}_{1}=$ no remarkable, 2 = considerable (significant, $p<.07$ ), $3=$ severe (highly significant, $p<.01$ ) treatment changes.

bobtained by summing the corresponding row of Table 1 ( $O / X$ was counted half).

cSame stimuli throughout ("familiar objects").

$\mathrm{d}$ The higher rating (3) refers to severe mediodorsal degeneration, the lower (2) to mild degeneration.

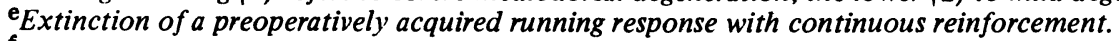

f Extinction of a postoperatively acquired manipulatory response with partial reinforcement.

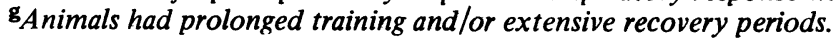


Table 3

F.elations Between Lesioned or Degenerated Brain Areas and Performance Impairment in Learning and Retention

\begin{tabular}{lll}
\hline \multicolumn{1}{c}{ Comparison } & $\mathrm{N}^{\mathrm{a}}$ & \multicolumn{1}{c}{$\mathrm{r}^{\mathrm{b}}$} \\
\hline Frontal cortex vs. impairment & 29 & -.134 \\
Prefrontal cortex vs. impairment & 29 & -.115 \\
Mediodorsal nucleus ${ }_{1}$ vs. impairment & 12 & $+.441^{*}$ \\
Mediodorsal nucleus ${ }_{2}$ vs. impairment & 11 & $+.507^{* *}$ \\
Ventral proreal gyrus vs. impairment & 30 & +.018 \\
Dorsal proreal gyrus vs. impairment & 30 & -.219 \\
Anterior sigmoid gyrus vs. impairment & 30 & -.197 \\
Posterior sigmoid gyrus vs. impairment & 30 & -.029 \\
Anterior orbital gyrus vs. impairment & 30 & +.056 \\
Anterior coronal gyrus vs. impairment & 30 & +.008 \\
Gyrus rectus vs. impairment & 29 & +.137 \\
Gyrus frontalis anterior vs. impairment & 29 & -.128 \\
Dorsolateral cortex (DLQ) vs. delayed & & \\
task performance & 8 & $-.793 * * *$ \\
Orbitofrontal cortex (OFQ) vs. performance & & \\
in inhibitory tasks & 8 & +.132 \\
Orbitofrontal cortex (OFQ) vs. performance & & \\
in inhibitory tasks & 7 & $+.884^{* * * *}$ \\
\hline
\end{tabular}

$\mathrm{a}_{N}=$ number of studies on which the correlation is based. For several correlations, the 30th study (Cornwell, 1966) was excluded because we were unable to determine the extent of the inner (gyrus rectus, gyrus frontalis anterior) lesions. Thalamic specifications were given in only part of the studies. The last correlation excludes Wagman's study (1968).

$\mathrm{b}_{r}=$ Spearman rank correlation coefficient, corrected for ties. ${ }^{*}=p<.08$ (one-tailed), ${ }^{* *}=p<.05$ (one-tailed), ${ }^{* * *}=p<.01$ (one-tailed, ${ }^{* * * *}=p<.005$ (one-tailed); all other correlations are not significant.

cComparison excludes the report of Warren (1964a), in which the frontal cats are the same as in Warren et al. (1972).

effects of such irrelevant variables as the strain, sex, and age of animals, variation of learning and retention measures, temporal factors, and surgical procedures.

Spearman rank correlation coefficients corrected for ties.were used, as this nonparametric statistic assumes an ordinal level of measurement only. It can also be applied appropriately under conditions where several ties occur because of the restricted range of a variable (Kendall, 1962; Siegel, 1956) (see also Table 4). Comparisons between the extent of lesions and postoperative performance levels were carried out in five kinds of experimental situations: (1) between frontal and prefrontal lesion size and performance levels on all task groups listed in Table 2, (2) between lesion size in specific areas of the frontal lobes and performance levels, $(3)$ between degree of mediodorsal degeneration and performance deficits, (4) between grouped "dorsolateral" lesions and achievement on various delayed tasks, and (5) between "orbitofrontal" lesions as a group and inhibitory tasks.

Investigations of the effects of frontal and prefruntal lesions in primates suggest the reasonableness of a functional distinction between a dorsolateral and an orbitofrontal region, the dorsolateral area being involved in delayed tasks (among other things), and the orbitofrontal in tasks requiring response inhibition (Manning, 1973; Rosvold, 1968). We therefore tried to correlate the results obtained in both of these groups of tasks with tentatively defined dorsolateral and orbitofrontal subfields, respectively. For each subregion, a quotient was defined, consisting, for the dorsolateral region, of the ratio of the total extent of lesions in the dorsal and ventral gyrus proreus (Gpd, Gpv), anterior sigmoid (Gsa), and anterior part of the frontal gyrus (Gfa) (summed and weighted one-half), to the extent of lesions in the gyri rectus $(\mathrm{Gr})$ and orbitalis anterior (Goa) (dorsolateral lesior. quotient or DLQ):

$$
D L Q=1 / 2[(G p d+G p v+G s a+G f a)] /[(G o a+G r)]
$$

The orbitofrontal lesion quotient (OFQ) consisted of the reciprocal of the dorsolateral quotient:

$$
\mathrm{OFQ}=2[(\mathrm{Goa}+\mathrm{Gr})] /[(\mathrm{Gpd}+\mathrm{Gpv}+\mathrm{Gsa}+\mathrm{Gfa})]
$$

OFQ and DLQ are reciprocals, as we assumed that in this way both quotients usually will have the largest values in the numerator. If so, almost linear interdependencies of the same kind will be possible between lesion types and learning results.

To evaluate the behavioral significance of the two indexes, the DLQ was correlated with performance deficit found in delayed tasks by Divac (1968, 1969, 1972, 1973, 1974), Lawicka and

Table 4

Orbitofrontal Cortex (OFQ) vs. Performance in Seven Inhibitory Tasks

\begin{tabular}{lccllll}
\hline \multicolumn{1}{c}{ Study } & $\begin{array}{c}\text { Impair- } \\
\text { ment }\end{array}$ & $\mathrm{OFQ}^{\mathbf{a}}$ & $\mathrm{R}_{\mathrm{I}}^{\mathbf{b}}$ & $\mathrm{R}_{\mathrm{OFQ}}^{\mathbf{c}}$ & $|\mathrm{D}|^{\mathbf{d}}$ & $\mathrm{D}^{2}$ \\
\hline Numan and & & & & & & \\
$\quad$ Lubar (1974) & 3 & 1 & 6 & 5 & 1 & 1 \\
Warren et al. (1969) & 2 & .8 & 3.5 & 2.5 & 1 & 1 \\
Warren et al. (1969) & 2 & .8 & 3.5 & 2.5 & 1 & 1 \\
Warren et al. (1969) & 1 & .8 & 1.5 & 2.5 & 1 & 1 \\
Warren et al. (1972) & 1 & .8 & 1.5 & 2.5 & 1 & 1 \\
Zielinski and & & & & & & \\
$\quad$ Czarkowska (1973) & 3 & 2 & 6 & 6.5 & .5 & .25 \\
Zielinski and & & & & & & \\
$\quad$ Czarkowska (1974) & 3 & 2 & 6 & 6.5 & .5 & .25 \\
\hline
\end{tabular}

$$
\begin{aligned}
\Sigma \mathrm{D}^{2} & =5.5 \\
\mathrm{r}_{\mathrm{S}} & =1-\frac{6 \Sigma \mathrm{D}^{2}}{\left(\mathrm{n}^{3}-\mathrm{n}\right)-\left(\mathrm{T}_{\mathbf{x}}+\mathrm{T}_{\mathrm{y}}\right)}=\frac{6 \cdot 5.5}{\left(7^{3}-7\right)-(18+33)} \\
& =+.884 \\
\mathrm{~T}_{\mathrm{x}} & =1 / 2\left[\left(2^{3}-2\right)+\left(2^{3}-2\right)+\left(3^{3}-3\right)\right]=18 \\
\mathrm{~T}_{\mathrm{y}} & =1 / 2\left[\left(4^{3}-4\right)+\left(2^{3}-2\right)\right]=33 \\
\text { Example of the calculation of an OFQ: }^{\mathrm{N}} \mathrm{OF} & \\
\mathrm{OFQ}^{\mathrm{e}} & =[2(\mathrm{Goa}+\mathrm{Gr})] /[(\mathrm{Gpd}+\mathrm{Gpv}+\mathrm{Gsa}+\mathrm{Gfa})] \\
& =[2(1+2) /[(2+2+1+1)] \\
& =1
\end{aligned}
$$

${ }^{a} A n X$ rating from Table 1 received a 3 , an $O / X$ rating a 2, and an 0 a 1 .

${ }^{\mathrm{b}}$ Rank of the impairment ratings.

${ }^{\text {CRank }}$ of the $O F Q$ ratings.

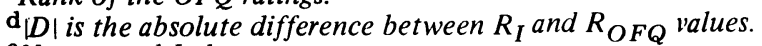

e Numan and Lubar. 
Konorski (1961), Thompson (1968), and Warren et al. (1962), and the OFQ was correlated with performance deficit in passive avoidance (Warren et al., 1972), extinction (Warren et al., 1969), go/no-go (Warren et al:, 1969; Zielinski \& Czarkowska, 1973, 1974), and DRL tasks (Numan \& Lubar, 1974; Wagman, 1968). In addition, a second correlation was obtained between OFQ and response inhibition, but omitting Wagman's study.

\section{Result,}

Table 3 presents the resulting correlations. Two types of analyses were conducted. First, impairment ratings of Columns 4 to 16 in Table 2 were correlated with the overall extents of ablated frontal and prefrontal cortex (second and third columns of Table 2), with the rated degree of mediodorsal degeneration (11th column of Table 1), and with the rated degree of destruction of each subarea, except the posterior part of the orbital gyrus, which was lesioned in only one of the 30 studies (Columns $2,3,4,5,6,8,9$, and 10 of Table 1). Secondly, similar impairment ratings were correlated with the above-mentioned DLQ and OFQ indexes (Equations 1 and 2), in which both quotients were recruited from Columns 2, 3, 4, 6, 9, and 10 of Table 1 . In ali comparisons (except those involving the DLQ and $O F Q$ ) in which deficits were evaluated in more than one task, an average deficit value was calculated from all tasks used. In the cases of the DLQ and OFQ, the only values used were those obtained in delayed response and response inhibition tasks, respectively, as, in these cases, we wanted to stress possible relations between specific tasks and specific brain portions. An example of the correlational procedure is shown in Table 4 . The Spearman rank correlation coefficient, corrected for ties, reads:

$$
r_{S}=1-\frac{6 \Sigma D^{2}}{\left(n^{3}-n\right)-\left(T_{x}+T_{y}\right)},
$$

where $T_{x}=1 / 2 \Sigma\left[\left(t_{x}^{3}-t_{x}\right)\right] ; T_{y}=1 / 2 \Sigma\left[\left(t_{y}^{3}-t_{y}\right)\right]$, and $i_{x}$ and $t_{y}$ are the frequency of ties in groups of the same rank, $n$ is the number of comparisons, and $\mathrm{D}^{2}$ is the squared sum of rank differences between lesion and impairment ratings.

As Table 3 shows, all comparisons between specific prefrontal subareas and task impairment turned out to be insignificant. Also nonsignificant were correlations between combined frontal and combined prefrontal lesions and performance deficils.

On the other hand, two significant direct relationships were found, cne between degeneration of the thalamic mediodorsal nucleus and task deficits and one between orbitofrontal lesions (tentatively defined) and performance of tasks requiring response inhibition (when Wagman's study is omitted). In addition, a significant negative correlation between lesions of the (tentatively defined) dorsolateral cortex and performance in delayed tasks was obtained.

\section{Discussion}

While most cat studies either failed to find specific anatomico-behavioral relations, or made no attempts to find them, there are nevertheless some reported data. Both of the extensive studies of Warren et al. $(1962,1972)$ looked for lesion-task correlations, but only the second of these found a task-specific trend towards a positive correlation between lesion extent and reversal learning deficits. Warren et al. (1962), on the other hand, gave a case report of an inverted relationship, the cat with the smallest lesion being most severely impaired in the delayed double alternation task.

Both Warren et al. (1969) and the present report established a significant correlation between the degree of mediodorsal degeneration and performance deficits. As the subprimate prefrontal area usually is defined as the cortical projection of the mediodorsal nucleus (Akert, 1964a; Leonard, 1969), these outcomes may be of considerable importance. They confirm anatomical approaches stressing the role of the cortico-subcortical interrelations, and they may encourage further search for topological and behavioral prefrontal homologies across species (Akert, 1964a).

Our attempt to distinguish a dorsolateral from an orbitofrontal region in the cat and to correlate the outcome of performance in specific tasks with magnitude of lesions in these two regions, as defined, yielded ambiguous results. Impairments in the inhibition of previously acquired response habits seem, in fact, to be somehow correlated with lesions of the subfield group herein called orbitofrontal. The significant negative correlation between deficits in delayed task performance and lesions in subfields called dorsolateral is mysterious at first sight.' Nevertheless, there are at least two possible explanations of this outcome. First, the relationship between dorsolateral lesions and severe delayed-task impairment does not seem to be typical for the cat, as was shown above. Second, primate studies have found that even the dorsolateral (and orbitofrontal) subregions can be split up further into functionally different parts (Goldman \& Rosvold, 1970; Iversen \& Mishkin, 1970; Stamm, 1973). Because of the lack of variation in the size of lesions reported in such studies, we were not able further to test a relationship between lesions in dorsolateral subregions and performance deficits, though it has been argued that the gyrus proreus ventralis, for example, might be an 
analogue of the principalis region of the primate dorsolateral region (Brutkowski, 1965; Numan \& Lubar, 1974).

We nevertheless hope that the tentative outcomes of the correlation approach will be confirmed by future experimental investigations. Of particular help herein would be a precise definition of the areas involved, combined with a careful choice of the learning tasks to be used. Such anatomical and behavioral preselection seems to be essential, as there are several reports that lesions in the same region produce quite different and/or unpredictable behavioral impairment even on similar and relatively simple tasks as exemplified by the finding of Warren et al. (1969) that lesions differentially affected extinction of pre- and postoperatively learned tasks. Furthermore, Manning (1973) has found in monkeys that a fixed-interval task dissociated well between dorsolateral and orbitofrontal lesioned monkeys, but a DRL task did not. On the anatomical side, there are findings of similar functional deficits for a variety of learning tasks after ablation of prefrontal or posterior association areas (Coutant, 1973, 1974; Warren et al., 1969), which probably are to be attributed to interruptions in the anatomical circuit between these and/or common subcortical areas.

\section{REFERENCES}

Ajmone-Marsan, C. The thalamus. Data on its functional anatomy and on some aspects of thalamo-cortical integration. Archives Italiennes de Biologie, 1965, 103, 847-882.

AKERT, K. Comparative anatomy of frontal cortex and thalamofrontal connections. In J. M. Warren \& K. Akert (Eds.), The frontal granular cortex and behavior. New York: McGraw-Hill, 1964. (a)

AkE RT, K. Discussion. In J. M. Warren \& K. Akert (Eds.), The frontal granular cortex and behavior. New York: McGraw-Hill, 1964. (b)

Akert, K., Orth, O., Harlow, H. F., \& Schlitz, K. A. Learned behavior of rhesus monkeys following neonatal bilateral prefrontal lobotomy. Science, 1960, 132, 1944-1945.

Albe-Fessard, D., \& Besson, J. M. Convergent thalamic and cortical projections-The nonspecific system. In A. Iggo (Ed.), Handbook of sensory physiology. (Vol. 2) Somatosensory system. Berlin: Springer, 1973.

Astruc, J. Cortico-cortical connections in the frontal cortex of the cat. Anatomical Record, 1969, 163, 148.

AUER, J. Terminal degeneration in the diencephalon after ablation of frontal cortex in the cat. Journal of Anatomy, 1956, 90, 30-41.

Axelrod, S., \& Diamond, I. T. Effects of auditory cortex ablation on ability to discriminate between stimuli presented to the two ears. Journal of Comparative and Physiological Psychology, 1965, 59, 79-89.

Batuev, A. S., Malyukova, A. V., \& Hohryakova, I. M. Structural and functional bases for frontal lobe participation in the organization of complex behavior in cats. Brain, Behavior and Evolution, 1974, 10, 290-306.

Bekerman, A. J., \& Encabo, H. Cortical control of the unit activity in nucleus medialis dorsalis thalami of the cat. Acta Neurobiologiue Experimentalis, 1972, 32, 151-176.

Beritashvili, J. S. Vertebrate memory. Characteristics and origin. New York: Plenum Press, 1971.
Beritashvili, J. S. The role of prefrontal lobes in psychonervous memory in vertebrates. Acta Neurobiologiae Experimentalis, 1972, 32, 657-672.

Boudreau, J. C., \& Tsuchitani, C. Sensory neurophysiology. With special reference to the cat. New York: Van Nostrand Reinhold, 1973.

Brodal, P. Corticopontine projections from proreate gyrus. Journal of Comparative Neurology, 1971, 142, 127-134.

Brutkowski, S. Prefrontal cortex and drive inhibition. In J. M. Warren \& K. Akert (Eds.), The frontal granular cortex and behavior. New York: McGraw-Hill, 1964.

BRUTKOWSKI, S. Functions of prefrontal cortex in animals. Physiological Reviews, 1965, 45, 721-746.

Buser, P., \& Bignall, K. E. Nonprimary sensory projection on the neocortex. International Review of Neurobiology, 1967, 10, 11-165.

Butter, C. M. Perseverazion in extinction and in discrimination reversal tasks following selective frontal ablations in macaca mulatta. Physiology and Behavior, 1969, 4, 163-171.

Cornwell, P. R. Behavioral effects of orbital and proreal lesions in cats. Journal of Companative and Physiological Psychology, 1966, 61, 50-58.

Coutant, L. W. Association cortex lesions and stimulus generalization in cats. Physiological Psychology, 1973, 1, 177-180.

Coutant, L. W. Association cortex lesions and Umweg behavior in cats. Journal of Comparative and Physiological Psychology, 1974, 86, 1083-1089.

Coutant, L. W., \& Warren, J. M. Reversal and nonreversal shifts by cats and rhesus monkeys. Journal of Comparative and Physiological Psychology, 1966, 61, 484-487.

Cronholm, J. N., Warren, J. M., \& HarA, K. Distribution of training and reversal learning by cats. Journal of Genetic Psychology, 1960, 96, 105-113.

Dabrowska, J. Dissociation of impairment after lateral and medial prefrontal lesions in dogs. Science, 1971, 171, 1037-1038.

DabrowsKa, J. On the mechanism of go-no go symmetrically reinforced tasks in dogs. Acta Neurobiologiae Experimentulis, 1972, 32, 345-359.

Diamond, I. T., \& Hall, W. C. Evolution of neocortex. Science, 1969, 164, 251-262.

Divac, 1. Effects of prefrontal and caudate lesions on delayed response in cats. Acta Biologiae Experimentalis, 1968, 28, 149-167.

Divac, 1. Delayed response in blind cats before and after prefrontal ablation. Physiology and Behavior, 1969, 4, 795-799.

Divac, I. Delayed alternation in cats with lesions of the prefrontal cortex and the caudate nucleus. Physiology and Behavior, 1972, 8, 519-522.

Divac, 1. Delayed response in cats after frontal lesion's extending beyond the gyrus proreus. Physiology and Behavior, 1973, 10, 717-720.

Divac, I. Caudate nucleus and relearning of delayed alternations in cats. Physiological Psychology, 1974, 2, 104-106.

Dubner, R. Single cell analysis of sensory interaction in anterior lateral and suprasylvian gyri of the cat cerebral cortex. Experimental Neurology, 1966, 15, 255-273.

Ebner, F. F., \& Myers, R. E. Distribution of corpus callosum and anterior commissure in cat and raccoon. Journal of Comparative Neurology, 1965, 124, 353-366.

ENCABO, H., \& RUARTE, A. C. Non-primary sensory projections of the fronto-orbital cortical area in the cat. Electroencephalography and Clinical Neurophysiology, 1967, 22, 210-219.

FELIX, D. Die Lokalisation der Summenaktionspotentiale im Stirnhirn der Katze nach elektrischer Reizung des Nucleus medialis dorsalis thalami. Schweizer Archiv fur. Neurologie, Neurochirurgie und Psychiatrie, 1969, 103, 209-248.

Fletcher, H. J. The delayed response problem. In A. M. Schrier, H. F. Harlow, \& F. Stollnitz (Eds.), Behavior of 
nonhuman primates (Vol. 1). New York: Academic Press, 1965.

FUSTER, J. M. Unit activity in prefrontal cortex during delayed-response performance: Neuronal correlates of transient memory. Journal of Neurophysiology, 1973, 36. $51-78$.

Glickstein, M., Quickley, W. A., \& Stebbins, W. C. Effect of frontal and parietal lesions on timing behavior in morikeys. Psychonomic Science, 1964, 1, 265-206.

Goldman, P., \& Rosvold, H. E. Localization of function within the dorsolateral prefrontal cortex of the rhesus monkey. Experimental Neurology, 1970, 27, 291-304.

Gross, C. G., \& Weiskrantz, L. Evidence of dissociation between impairment on auditory discrimination and delayed response in frontal monkeys. Experimental Neurology, $1962,5,453-476$.

Gross, C. G., \& Weiskrantz, L. Some changes in behavior produced by lateral frontal lesions in the macaque. In J. M. Warren \& K. Akert (Eds.), The frontal granular cortex and behavior. New York: McGraw-Hill, 1964.

Guillery, R. W. Afferent fibers to the dorsomedial thalamic nucleus in the cat. Journal of Anatomy, 1959, 93, 403-419.

HANNon, R., \& BADER, A. A comparison of frontal pole, anterior median and caudate nucleus lesions in the rat. Physiology and Behavior, 1974, 13, 513-521.

Harlow, H. F., Blanquist, A. J., Thompson, C. I., Schlitz, K. A., \& Harlow, M. K. Effects of induction age and size of trontal lobe lesions on learning in rhesus monkeys. In R. Isaacson (Ed.), The neuropsychology of development. New York: Wiley, 1968.

HASSLER, R. Extrapyramidal motor areas of cat's frontal lobe: Their functional and architectonic differentiation. International Journal of Neurology, 1966, 5, 301-316.

Heath, C. J., \& Jones, E. G. The anatomical organization of the suprasylvian gyrus of the cat. Ergebnisse der Anatomie und Entwicklungsgeschichte, 1971, 45, 1-64.

Hirayoshi, 1., \& WarRen, J. M. Overtraining and reversal learning by experimentally naive kittens. Jourmal of Compurative and Physiological Psychology, 1967, 64, 507-510.

Iversen, S. D., \& Mishkin, M. Perseverative interference in monkeys following selective lesions of the inferior prefrontal convexity. Experimental Brain Research, 1970, 11, 376-386.

JACOBSEN, C. F. Functions of the frontal association area in primates. Archives of Neurology and Psychiatry, 1935, 33, 558-569.

JACOBSEN, C. F. Studies of cerebral function in primates: 1. The functions of the frontal association area in monkeys. Comparative Psychology Monographs, 1936, 13, 3-60.

KENDALL, M. G. Rank correlation methods (3rd ed.). London: Griffin, 1962.

Khalifeh, R. R., Kaglber, W. W., \& INGRam, W. R. Some efferent connections of the nucleus medialis dorsalis. An experimental study in the cat. American Journal of Anatomy, $1965,116,341-354$.

Kolb, B., Nonneman, A. J., \& Singh, R. K. Double dissociation of spatial impairments and perseveration following selective prefrontal lesions in the rat. Journal of Comparative and Physiological Psychology, 1974, 87, 772-780.

KoNORSKI, J. Some hypotheses concerning the functional organization of prefrontal cortex. Acta Neurobiologiae Experimentalis, 1972, 32, 595-613.

KonORSKı, J. The role of prefrontal cortex in the programming of motor behavior. In J. D. Maser (Ed.), Effferent organization and the integration of behavior. New York: Academic Press. 1973.

Kramer, T. J., \& Rilling, M. Differential reinforcement of low rates: A selective critique. Psychological Bulletin, 1970, 74, 225.254

KREINER, J. The neocortex of the cat. Acta Neurobiologiae Experimentalis, 1971, 31, 151-201.

LAwicka, W. Physiological mechanisms of delayed reaction.
1I. Delayed reactions in dogs and cats to directional stimuli. Acta Biologiae Experimentalis, 1959, 19, 199-220.

LAWICKA, W. A proposed mechanism for delayed response impairment in prefrontal animals. Acta Biologiae Experimentulis, 1969, 29, 401-414.

LAWICKA, W., \& KonORSKI, J. The effects of prefrontal lobectomies on the delayed responses in cats. Acta Biologiae Experimentalis, 1961, 21, 141-156.

LeONARD, C. M. The prefrontal cortex of the rat. I. Cortical projection of the mediodorsal nucleus. II. Efferent connections. Brain Research, 1969, 12, 321.343.

llamas, A., Reinoso-Suarez, F., \& Martinez-Moreno, E. Projections to the gyrus proreus from the brain stem tegmentum (locus coeruleus, raphe nuclei) in the cat, demonstrated by retrograde transport of horseradish peroxidase. Brain Research, 1975, 89, 331-336.

LuRIA, A. R. The frontal lobes and the regulation of behavior. In K. H. Pribram \& A. R. Luria (Eds.), Psychophysiology of the frontal lobes. New York: Academic Press, 1973.

Manning, F. J. Performance under temporal schedules by monkeys with partial ablations of prefrontal cortex. Physiology and Behavior, 1973, 11, 563-569.

Masterton, B., \& Berkiey, M. A. Brain function: Changing ideas on the role of sensory, motor, and association cortex in behavior. Annual Review of Psychology, 1974, 25, 277-312.

Masterton, B., \& Skeen, L. C. Origins of anthropoid intelligence: Prefrontal system and delayed alternation in hedgehog, tree shrew, and bush baby. Journal of Comparative and Physiological Psychology, 1972, 81, 423-433.

Mayers, K. S., Robertson, R. T., Rubel, E. W., \& Thompson, R. F. Development of polysensory responses in association cortex of kitten. Science, 1971, 171, 1038-1040.

Mettler, F. A. The corticothalamic projection: The structural substrate for the control of the thalamus by the cerebral cortex. In T. L. Frigyesi, E. Rinvik, \& M. D. Yahr (Eds.), Corticothalamic projections and sensorimotor activities. New York: Raven Press, 1972.

Mishikin, M. Perseveration of central sets after frontal lesions in monkeys. In J. M. Warren \& K. Akert (Eds.), The frontal granular cortex and behavior. New York: McGraw-Hill, 1964.

Mishkin, M., Vest, B., Waxier, M., \& Rosvold, H. E. A reexamination of the effects of frontal lesions on object alternation. Neuropsychologia, 1969, 7, 357-363.

Moniz, E. Tentatives opératoires dans le traitement de certuin psychoses. Paris: Masson, 1936.

NautA, W. J. H. The problem of the frontal lobe: A reinterpretation. Journal of Psychiatric Research, 1971. $8,167-187$.

Nauta, W. J. H. Neural associations of the frontal cortex. Acta Neurobiologiae Experimentalis, 1972, 32, 125-140.

Nielson, H. C., \& Davis, K. B. Effect of frontal ablation upon conditioned responses. Journal of Comparative and Physiologicul Psychology, 1966. 61, 380-387.

$\mathrm{N}_{\mathrm{K} I}, \mathrm{H}$. Prefrontal unit activity during delayed alternation in the monkey. I. Relation to direction of response. Brain Research, 1974, 68, 185-196. (a)

NıKı. H. Prefrontai unit activity during delayed alternation in the monkey. II. Relation to absolute vs relative direction of response. Bruin Research, 1974, 68, 197-204. (b)

Nıkı, H. Differential activity of prefrontal units during right and left delayed response trials. Brain Research, 1974, 70, 346-349. (c)

Numan, R., \& LuBER, J. F. Role of the proreal gyrus and septal area in response modulation in the cat. Neuropsychologie. 1974, 12, 213-234.

OsCAR-BERman, M. The effects of dorsolateral-frontal and ventrolateral-orbitofrontal lesions on spatial discrimination learning and delayed response in two modalities. Neuropsychologia, 1975, 13, 237.246.

Passingham, R. E. Visual discrimination learning after selective 
prefrontal ablations in monkeys (macaca mulatta). Neuropsychologia, 1972, 10, 27-39. (a)

Passingham. R. E. Non-reversal shifts after selective prefrontal ablations in monkeys (macaca mulatta). Neuropsychologia, 1972, 10, 41-46. (b)

Passingham, R. E., \& Etrlinger, G. Tactile discrimination learning after selective prefrontal ablations in monkeys (macaca mulatta). Neuropsychologia, 1972, 10, 17-26.

Ронц, W. Dissociation of spatial discrimination deficits following frontal and parietal lesions in monkeys. Journal of Compurative and Physiological Psychology, 1973, 82, 227-239.

Pribram, K. H. On the neurology of thinking. Behavioral Science, 1959, 4, 265-289.

Pribram, K. H. The primate frontal cortex-executive of the brain. In K. H. Pribram \& A. R. Luria (Eds.), Psychophysiology of the frontal lobes. New York: Academic Press, 1973.

Rabinovitch, N. S., \& Rosvold, H. E. A close-field intelligence test for rats. Canadian Journal of Psychology, $1951,5,122 \cdot 128$.

Raisman, G. Some aspects of the neural connections of the hypothalamus. In L. Martini, M. Motta, \& F. Fraschini (Eds.), The hypothalamus. New York: Academic Press, 1970.

Reinoso-SuAREz, F. Topographischer Hirnatlas der Katze tür experimental-physiologische Untersuchungen. Darmstadt: E. Merck AG, 1961.

Richelle, M. Temporal regulation of behavior and inhibition. In R. A. Boakes \& M. S. Halliday (Eds.), Inhibition and learning. New York: Academic Press, 1972.

Rinvik, E. The corticothalamic projection from the gyrus proreus and the medial wall of the rostral hemisphere in the cat. An experimental study with silver impregnation methods. Experimental Brain Research, 1968, 5, 129-152. (a)

Rinvik, E. The corticothalamic projection from the pericruciate and coronal gyri in the cat. An experimental study with silver impregnation methods. Brain Research, 1968, 10, 79-119. (b)

Rose, J. E., \& Woolsey, C. N. The orbitofrontal cortex and its connections with the mediodorsal nucleus in rabbit, sheep, and cat. Research Publications of the Association for Research in Nervous and Mental Disease, 1948, 27, 210-232.

Rosvold, H. E. The prefrontal cortex and caudate nucleus: A system for effecting correction in response mechanisms. In C. Kupp (Ed.), Mind as a tissue. New York: Harper \& Row, 1968.

Rosvold, H. E., \& Mishxin, M. Non-sensory effects of frontal lesion on discrimination learning and performance. In J. F. Delatresnaye (Ed.), Brain mechanisms and leaming. Oxford: Blackwell, 1961.

Siecel, A., Edinger, H., \& Lowenthal, H. Effects of electrical stimulation of the medial aspect of the prefrontal cortex upon attack behavior in cats. Brain Research, 1974, 66, $467-479$.

SIEGEl, S. Nonparametric statistics: For the behavioral sciences. New York: McGraw-Hill, 1956.

Sтамм, J. S. Functional dissociation between the inferior and arcuate segments of dorsolateral prefrontal cortex in the monkey. Neuropsychologia, 19i3, 11, 181-190.

Stamm, J. S., \& Rosen, S. C. Electrical stimulation and steady potential shifts in prefrontal cortex during delayed response performance by monkeys. Acta Biologiae Experimentalis, 1969, 29, 385.399.

Stamm, J. S., \& Rosen, S. C. Cortical steady potential shifts and anodal polarization during delayed response performance. Acta Neurobiologiae Experimentalis, 1972, 32, 193.209.

STEPIEN, :. The magnet reaction, a symptom of prefrontal ablation. Acta Neurobiologiae Experimentalis, 1974, 34, $145-160$.

Stepien, I., Stepien, L., \& Sychowa, B. Disturbances of motor conditioned behaviour following bilateral ablations of the pericruciate area in dogs and cats. Acta Biologiae Experimentalis, 1966, 26, 323-340.

Teitelbaum, H. A comparison of effects of orbito-frontal and hippocampal lesions upon discrimination learning and reversal in the cat. Experimental Neurology, 1964, 9, 452.462 .

TÉUBER, H. - L. The riddle of frontal lobe in man. In J. M. Warren \& K. Akert (Eds.), The frontal granular cortex and behavior. New York: McGraw-Hill, 1964. (a)

Teuber, H.-L. Discussion. In J. M. Warren \& K. Akert (Eds.), The frontal granular cortex and behavior. New York: McGraw-Hill, 1964. (b)

Teuber, H.-L. The frontal lobes and their function: Further observations on rodents, carnivores, subhuman primates, and man. International Joumal of Neurology. $1966,5,282-300$.

Teuber, H.-L. Unity and diversity of frontal lobe functions. Acta Neurobiologiae Experimentalis, 1972, 32, 615-656.

Thompson, R. F., Johnson, R. H., \& Hoopes, J. J. Organization of auditory, somatic sensory and visual projection to association fields of cerebral cortex in the cat. Journal of Neurophysiology, 1963, 26, 343-364.

Thompson, V. E. Neonatal orbitofrontal lobectomies and delayed response behavior in cats. Physiology and Behavior, $1968,3,631-636$.

VoneIDA, T. J., \& RoYce, G. J. Ipsilateral connections of of gyrus proreus in the cat. Brain Research, 1974, 76, 393-400.

Voneida, T. J., \& Trevarthen, C. An experimental study of transcallosal connections between the proreus gyri of the cat. Brain Research, 1969, 12, 384-395.

Wagman, A. M. I. The effect of frontal lobe lesions upon behavior requiring use of response-produced cues. Journal of Comparative and Physiological Psychology, 1968 , 66, 69-76.

WALler, W. H. Thalamic connections of frontal cortex in the cat. Journal of Comparative Neurology, 1940, 73. $117-138$

Warren, J. M. Perseverative reactions in chicks and kittens. Journal of Psychology, 1959, 47, 9-12.

WARREN, J. M. The behavior of carnivores and primates with lesions in the prefrontal cortex. In J. M. Warren \& K. Akert (Eds.), The frontal granular cortex and behavior. New York: McGraw-Hill, 1964.

WARREN, J. M. Primate learning in comparative perspective. In A. M. Schrier, H. F. Harlow, \& F. Stollnitz (Eds.), Behavior of nonhuman primates (Vol. 1). New York: Academic Press, 1965.

W ARREN, J. M. Reversal learning and the formation of learning sets by cats and rhesus monkeys. Journal of Compurative and Physiological Psychology, 1966, 61, 421-428.

WARREN, J. M. Learning in vertebrates. In D. A. Dewsbury \& D. A. Rethlingshafer (Eds.), Comparative psychology: A modern survey. New York: McGraw-Hill, 1973.

Warren, J. M., Coutant, L. W., \& Cornwell, P. R. Cortical lesions and response inhibition in cats. Neuropsychologia, 1969, 7, 245-257.

WARren, J. M., \& Warren, H. B. Performance of immature and adult cats on the Hamilton search test. Psychonomic Science, 1966, 6, 5-6.

Warren, J. M., Warren, H. B., \& Akert, K. Umweg learning by cats with lesions in the prestriate association cortex. Journal of Comparative and Physiological Psychology, $1961,54,629-632$.

W ARREN, J. M., WARREN, H. B., \& AKert, K. Orbitofrontal cortical lesions and learning in cats. Journal of Comparative Neurology, 1962, 118, 17-41.

WARREN, J. M., WARREN, H. B., \& AKERT, K. The behavior of chronic cats with lesions in the frontal association cortex. Actu Neurobiologiae Experimentalis, 1972, 32. 361.392 .

Watanabe, K. Delayed response: A review. Waseda Psycho- 
lugical Reports, 1974, 6, 2-12. (In Japanese).

WEBSTER, K. E. The cortico-striatal projection in the cat. Journal of Anatomy, 1955, 99, 329-337.

Weiskrantz, L. Memory. In L. Weiskrantz (Ed.). Anulysis of behavioral change. New York: Harper \& Row, 1908.

Wikmark. G.. \& Warren, J. M. Delaved response learning by cage-reared normal and prefrontal cats. Psichonomic Science, 1972, 26, 243-245.

Wold. J. E.. \& Brodal, A. The cortical projection of the orbital and proreate gyri to the sensory trigeminal nuclei in the cat. An experimental anatomical study. Brain Reseurch. 1974. 65. 381-395.

YARBRough. J. U. Delayed reaction with sound and lights in cats. Journal of Animal Behavior, 1917, 7. 87-110.

Zielinski, K. Retention of the avoidance retlex after pretrontal lobectomy in cats. Acta Biologiae Experimentulis. 1900, 26, 167-181.

ZIELINSKI. K. Retention of the escape reflex after prefrontal lobectomy in cats. Acta Neurobiologiae Experimentulis. 1970. 30. 43-57.

Zielinski. K. Effects of prefrontal lesions on avoidance and escape retlexes. Actu Neurubiologiae Experimentulis, 1972. 32. $393-415$. (a)

ZiELINSKI. K. Stimulus intensity and prefrontal lesion effects un tatencies of the bar-pressing responses in cats. Bulletin de liAcudémie Polonuise des Sciences. Serie des Sciences Biologiques, 1972. 20.821-826. (b)

ZieliNiskI. $K$. Changes in avoidance response latencies after prefruntal lesions in cats: Group versus individual data. Actu Neurobiologiae Experimentalis, 1974. 34. 477.490.

ZiELINSKI. K.. \& CZARKowsKa, J. Go-no go avoidance retlex differentiation and its retention after prefrontal lesion in cats. Actu Neurubiologiue Experimentalis. 1973. 33. 40--490.

Zielinski, K.. \& Czarkowska, J. Quality of stimuli and prefrontal lesions effects on reversal learning in go-no go avoidance reflex differentiation in cats. Acta Neurobiologiue Experimentulis, 1974, 34, 43-68.

\section{NOTE}

1. We hate also computed eight additional correlation, with various meaningtul combinations of only one. two. or three lesioned areas in the numerator. Four confirmed a signiticant negative relationship ( $p<.05$, two-tailed), the rest were nunsig. nificant.

(Received for publication December 8, 1975; revision accepted March 2, 1976.) 